\title{
The relationship between discrete and ongoing cerebral events
}

\author{
A. SALAMY, P. E. BUTLER, J. L. McFARLAND, and W. A. HARGREAVES \\ University of California, San Francisco, California 94143
}

\begin{abstract}
An attempt was made to determine the relationship between the somatosensory evoked response (SER) and preceding EEG activity. A canonical correlational analy sis of a number of parameters derived from both prestimulus and poststimulus cerebral events revealed a complex pattern of relatedness between the two sets of electroencephalographic variables. However, the contribution made by each parameter to the canonical correlation showed little consistency across Ss. Moreover, the amount of variance in one set of parameters accounted for by the other set was relatively small. It was concluded that the SER, as recorded from the vertex, is essentially independent of ongoing EEG rhy thms.
\end{abstract}

Attempts to determine the relationship between some parameter (amplitude or latency) of the sensory evoked response (ER) and some parameter (amplitude or frequency) of the prestimulus electroencephalogram (EEG) have produced discrepant results. While some investigators report a direct relationship between average EEG amplitude and certain components of the ER (Dustman \& Beck, 1965; Rodin, Grisell, Gudobba, \& Zachary, 1965), others have found that an inverse relationship holds between the two variables (Fruhstorfer \& Bergstrom, 1969). The strength and direction of the correlation dependended to some extent on the segment of the ER wave form measured and on the modality stimulated. Generally speaking, it was the late components of the visual ER that showed a positive relationship to the amount of alpha activity.

Using the frequency of the background EEG as the criterion, Spilker, Kamiya, Callaway, and Yeager (1969) found that Ss trained to "control" their alpha rhythm produced larger ERs to flashes and sine wave light in the presence of the induced rhythm. On the other hand, click ERs showed no apparent relationship to the alpha state.

Still others have been unable to establish any consistent relationship between the ER and contiguously recorded EEG (Chapman \& Bragdon, 1964; Garcia-Austt, 1963; Shagass, Overton, Bartolucci, \& Straumanis, 1971; Werre \& Smith, 1964). Wide variation in the number of ERs averaged, as well as marked differences in the length of the prestimulus EEG measured, has, no doubt, contributed to the inconclusive results.

The purpose of this experiment was to reexamine the relationship(s) between the ER and ongoing EEG as based on single-trial data (prestimulus and poststimulus) and on short (1-sec) EEG epochs.

\section{METHOD}

live healthy male graduate students served as Ss. All consistently displayed single, unaveraged somatosensory LRs that were large enough with respect to the background EEG to permit accurate measurements to be made (see lig. 1 ).
Sixty-four single cortical responses evoked by brief (500-microsec) electrical shocks $(8-11 \mathrm{~mA})$, delivered (Grass S8 stimulator with isolation unit) precutaneously to the median nerve of the right wrist, were obtained from each S. The stimuli were presented randomly between 4 and $20 \mathrm{sec}$. The electroencephalogram was recorded (Grass Model 6) exclusively from the vertex $(C z)$ referred to linked ears $\left(A_{1}-A_{2}\right)$. Each ER was singularly fed through a Fabritek signal averager (Model 1062) and written out (Hewlett-Packard XY plotter) on graph paper to facilitate quantification.

Period analysis (biophysical encoders) and amplitude integration (modified method of Drohocki) of the primary EEG tracing was performed on the 1-sec epochs preceding each stimulus pulse and read out as vertical pen deflections on separate channels of the EEG recorder. Only the major periods (zero crossings) of theta $(4-7 \mathrm{~Hz})$, slow alpha $(8-10 \mathrm{~Hz})$, fast alpha $(10.2-13 \mathrm{~Hz}$ ), and the intermediate period (peaks) of beta $(16-32 \mathrm{~Hz})$ activity were included in the analysis. Since beta waves often appear as riding (superimposed) activity, that is to say, they do not cross the baseline, a measure of the points of zero slope was obtained by taking the mathematical first derivative of the primary EEG tracing.

The pulses generated for each EEG parameter were then counted for each case $(N=64)$ and tallied for each $S$. The amplitude and latency of the first large negative $\left(\mathrm{N}_{1}\right)$ and second large positive $\left(\mathrm{P}_{2}\right)$ components of the vertex ER were measured for each response in microvolts and milliseconds, respectively. It is these components that are most consistent across Ss. The selected peaks $\left(\mathrm{N}_{1}, \mathrm{P}_{2}\right)$ were identified by the template method described elsewhere (Salamy, 1973). The five EEG parameters and four ER parameters formed the two sets of original variables to be tested in a canonical analysis (BMD package, X75, Dixon, (1970). With this procedure, each independent multivariate relationship existing between the original set of variables can be defined.

\section{RESULTS}

Table 1 (A-E) shows the canonical correlations and the corresponding coefficient vectors for each $\mathrm{S}$. The first correlation listed represents the maximum possible correlation between any' weighted sum of the EEG variables and any other weighted sum of the ER variables (composite scores). The coefficients shown below each correlation reveal which variables in each set are involved in that correlation. For example, in the first column of Table 1-A, it can be seen that a combination of EEG variables which heavily emphasizes fast alpha 


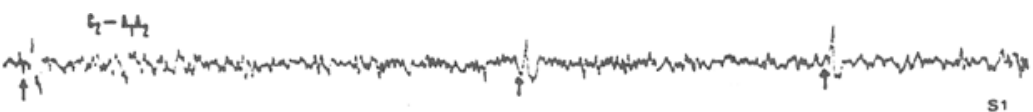
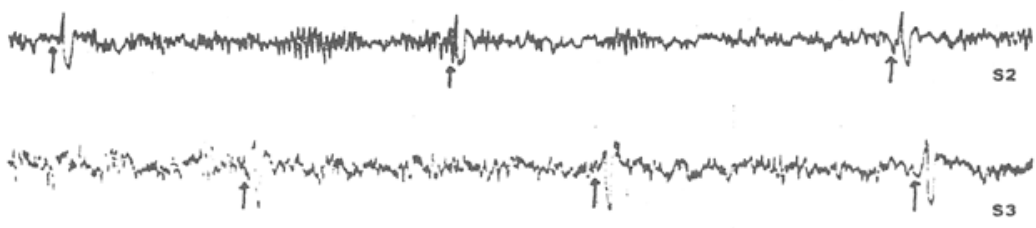

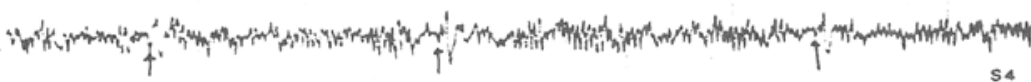

Fig. 1. Lnaveraged ERs and ongoing EEG. This figure illustrates the magnitude of the sensory $E R$ with respect to the background EEG. Note the ease in which the peaks of interest $\left(N_{1}, P_{2}\right)$ can be identified for each $S$ (S 1-S 5). Measurements of the ER, however. were not made from the primary trace (see text). Arrows indicate points of stimulus presentation. Negativity at $\mathrm{Cz}$ is indicated by an upward deflection.

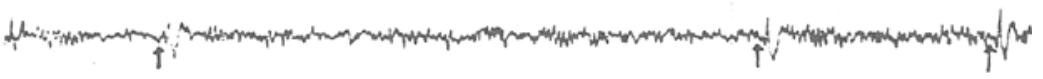

Table 1

Canonical Correlations for Five Subjects (A-E)

\begin{tabular}{|c|c|c|c|c|}
\hline \multirow{2}{*}{$\begin{array}{l}\text { A } \\
\text { Variable }\end{array}$} & \multicolumn{4}{|c|}{ Canonical Correlations } \\
\hline & $\begin{array}{c}1 \\
0.463\end{array}$ & $\stackrel{2}{0.349}$ & $\begin{array}{c}3 \\
0.243\end{array}$ & $\begin{array}{c}4 \\
0.199 \\
\end{array}$ \\
\hline \multicolumn{5}{|c|}{$\begin{array}{c}\text { Coefficients for Canonical Variables of the } \\
\text { First Set (EEG Parameters) }\end{array}$} \\
\hline $\begin{array}{l}1 \\
2 \\
3 \\
4 \\
5\end{array}$ & $\begin{array}{r}-0.198 \\
0.493 \\
0.917 \\
0.158 \\
-0.066\end{array}$ & $\begin{array}{r}0.885 \\
0.022 \\
-0.064 \\
0.198 \\
-0.303\end{array}$ & $\begin{array}{r}-0.368 \\
-0.176 \\
-0.265 \\
0.246 \\
-0.401\end{array}$ & $\begin{array}{r}-0.372 \\
0.632 \\
-0.370 \\
0.494 \\
0.172\end{array}$ \\
\hline \multicolumn{5}{|c|}{$\begin{array}{l}\text { Coefficients for Canonical Variables of } \\
\text { the Second Set (ER Parameters) }\end{array}$} \\
\hline $\begin{array}{l}6 \\
7 \\
8 \\
9 \\
\end{array}$ & $\begin{array}{r}-0.508 \\
1.126 \\
0.304 \\
0.315 \\
\end{array}$ & $\begin{array}{r}0.606 \\
-0.179 \\
0.077 \\
-0.963 \\
\end{array}$ & $\begin{array}{r}0.522 \\
-0.469 \\
0.909 \\
0.445 \\
\end{array}$ & $\begin{array}{r}-0.826 \\
-0.047 \\
0.397 \\
-0.121 \\
\end{array}$ \\
\hline$B$ & \multicolumn{4}{|c|}{ Canonical Correlations } \\
\hline Variable & $\begin{array}{c}1 \\
0.326\end{array}$ & $\begin{array}{c}2 \\
0.262 \\
\end{array}$ & $\begin{array}{c}3 \\
0.159 \\
\end{array}$ & $\begin{array}{c}4 \\
0.102 \\
\end{array}$ \\
\hline \multicolumn{5}{|c|}{$\begin{array}{c}\text { Coefficients for Canonical Variables of the } \\
\text { First Set (EEG Parameters) }\end{array}$} \\
\hline $\begin{array}{l}1 \\
\frac{1}{3} \\
4 \\
5\end{array}$ & $\begin{array}{r}0.578 \\
-0.422 \\
0.480 \\
-0.287 \\
0.648\end{array}$ & $\begin{array}{r}0.053 \\
-0.323 \\
0.501 \\
-0.113 \\
-0.646\end{array}$ & $\begin{array}{r}0.091 \\
-0.980 \\
-0.890 \\
-0.073 \\
-0.644\end{array}$ & $\begin{array}{r}-0.211 \\
0.034 \\
-0.118 \\
-0.976 \\
0.017\end{array}$ \\
\hline \multicolumn{5}{|c|}{$\begin{array}{l}\text { Coefficients for Canonical Variables of } \\
\text { the Second Set (ER Parameters) }\end{array}$} \\
\hline $\begin{array}{l}6 \\
7 \\
8 \\
9 \\
\end{array}$ & $\begin{array}{l}0.705 \\
0.458 \\
0.315 \\
0.210 \\
\end{array}$ & $\begin{array}{r}-0.749 \\
0.900 \\
0.229 \\
-0.195 \\
\end{array}$ & $\begin{array}{r}-0.211 \\
-0.137 \\
0.497 \\
0.848 \\
\end{array}$ & $\begin{array}{r}0.121 \\
-0.297 \\
0.770 \\
-0.459 \\
\end{array}$ \\
\hline$C$ & \multicolumn{4}{|c|}{ Canonical Correlations } \\
\hline Variable & $\begin{array}{c}1 \\
0.472\end{array}$ & $\stackrel{2}{0.288}$ & $\begin{array}{c}3 \\
0.197\end{array}$ & $\begin{array}{c}4 \\
0.151\end{array}$ \\
\hline
\end{tabular}

Coefficients for Canonical Variables of the First Set (EEG Parameters)

\begin{tabular}{|c|c|c|c|c|}
\hline & -0.788 & -0.491 & -0.287 & 0.267 \\
\hline & 0.428 & -0.351 & 0.326 & -0.428 \\
\hline & 0.130 & -0.618 & 0.651 & 0.006 \\
\hline
\end{tabular}

$$
\begin{array}{lrrrr}
4 & -0.172 & -0.363 & -0.504 & -0.795 \\
5 & 0.599 & -0.572 & -0.467 & 0.381
\end{array}
$$

Coefficients for Canonical Variables of the Second Set (ER Parameters)

\begin{tabular}{lrrrr}
6 & -0.324 & -1.006 & -0.262 & -0.401 \\
7 & 0.219 & -0.052 & 0.417 & 0.991 \\
8 & 0.250 & -0.124 & 0.972 & -0.414 \\
9 & -0.920 & 0.560 & 0.009 & 0.412 \\
\hline D & \multicolumn{4}{c}{ Canonical Correlations } \\
\cline { 2 - 5 } Variable & 0.366 & 0.155 & 0.111 & 0.091 \\
\hline
\end{tabular}

Coefficients for Canonical Variables of the First Set (EEG Parameters)

$\begin{array}{rrrrr}1 & 0.014 & 0.415 & -0.082 & 0.360 \\ 2 & 0.357 & 0.590 & 0.794 & 0.076 \\ 3 & -0.027 & -0.327 & 0.984 & -0.052 \\ 4 & -0.036 & -0.192 & 0.253 & 0.959 \\ 5 & -0.786 & 0.577 & 0.629 & 0.008\end{array}$

Coefficients for Canonical Variables of the Second Set (ER Parameters)

\begin{tabular}{ccccr}
6 & \multicolumn{5}{c}{ the Second Set (ER Parameters) } \\
7 & 0.390 & 0.790 & -1.000 & -0.250 \\
8 & 0.687 & -0.552 & 0.924 & 0.427 \\
9 & -0.253 & -0.298 & -0.171 & 1.126 \\
& -0.200 & 0.994 & 0.505 & -0.374 \\
\hline E & 1 & \multicolumn{5}{c}{ Canonical } & Correlations \\
Variable & 0.314 & 0.239 & 0.217 & 0.124 \\
\hline
\end{tabular}

Coefficients for Canonical Variables of the First Set (EEG Parameters)

$\begin{array}{rrrrr}1 & -0.236 & 0.610 & -0.566 & -0.064 \\ 2 & -0.229 & -0.505 & -0.767 & 0.330 \\ 3 & 0.297 & 0.591 & 0.161 & 0.602 \\ 4 & -0.811 & 0.146 & 0.383 & 0.414 \\ 5 & 0.464 & -0.032 & -0.224 & 1.044\end{array}$

Coefficients for Canonical Variables of the Second Set (ER Parameters)

\begin{tabular}{rrrrr}
6 & -0.793 & -0.376 & 0.603 & 0.805 \\
7 & 0.566 & 0.239 & -1.243 & -0.098 \\
8 & -0.545 & -0.335 & 0.195 & 0.844 \\
9 & 0.721 & -0.670 & 0.269 & 0.138 \\
\hline
\end{tabular}

Variables: 1-integrated amplitude. 2-slow alpha. 3-fast alpha. 4-beta. 5-theta. 6-amplitude of $V_{1} .7$-amplitude of $P_{2}$. 8 -latency of $\mathrm{r}_{1}$. 9-latency of $P_{2}$ 
(variable, 3) correlates 0.463 with a weighted sum of EP variables which emphasizes amplitude of $P_{2}$ (variable, 7 ) and. to a lesser extent, amplitude of $\mathrm{N}_{1}$ (variable, 6). In general, the relative size of the coefficients indicate the variables in each set (EEG and ER) which contribute to a particular correlation. In this respect, the coefficients have the same interpretation as factor coefficients ("loadings") in factor analysis. As in factor analysis, a single canonical correlation may not explain all the variance in the data. Thus, several canonical correlations are computed for each $\mathrm{S}$, with the restriction that they be mutually independent.

While the simple correlation (Pearson product moment correlation, not shown) between each parameter generally approached zero, irrespective of direction, the first-order canonical correlation revealed a moderate degree of association between the composite prestimulus and poststimulus events. This relationship, however, appears to be very complex. That is to say, the relative contribution made by each of the original variables to the composite score. as indicated by the weighting coefficients, was quite variable from $\mathrm{S}$ to $\mathrm{S}$.

Since the square of the canonical correlation may be interpreted as the amount of variance in one composite score that is accounted for by the other composite score. it can be seen that even the best linear combination among the variables of each set explained only about $10 \%-20 \%$ of the total variance. This value is in agreement with data based on small averages (Salamy. 1972).

\section{DISCUSSION}

These findings indicate that the vertex slow waves evoked by somatic afferent stimulation are relatively independent of ongoing EEG activity. A similar conclusion was reached by Shagass, Overton, Bartolucci, and Straumanis (1971) for the postrolandically recorded somatosensory ER in adults and by Tanguay and Ornitz (1972) for the auditory ER in sleeping children. In both of these studies. a varying number of ERs were averaged during markedly different electrophysiological states of consciousness (e.g., EEG arousal while TV viewing, Stage II sleep and Stage REM sleep). Fluctuations in the amplitude of the ER did not parallel the striking EEG changes. In the present experiment, the Ss' vigilance level was maintained in an alert. but relaxed. state. We found no evidence to suggest that a particular characteristic of a fairly constant EEG signal correlated well with any of several ER parameters that followed. Despite the stability of the overall EEG pattern, there was sufficient trial-to-trial variation in the integrated amplitude and specific frequency bands (theta, slow alpha, fast alpha, beta) as well as the ER measures to permit a reasonable distribution of each variable to be sampled.

The question remains. however, as to whether or not the extremely large sensory potentials (see Fig. 1) could have "washed out" any preexisting relationships with ongoing EEG activity. In this regard, virtually the same allocation of variance was found for the identical EEG variables following the administration of alcohol to the same Ss when the single ERs were completely obscured by background activity (Salamy, 1972).

\section{REFERENCES}

Chapman, R. W., \& Bragdon, R. H. Evoked responses to numerical and nonnumerical visual stimuli while problem solving. Nature, 1964, 203, 1155-1157.

Dixon, W. J. (Ed.) Biomedical computer programs. $X$-series supplement. Los Angeles: University of California Press, 1970. Pp. 113-122.

Dustman, R. E., \& Beck, E. T. Phase of alpha brain waves, reaction time and visually evoked potentials. Electroencephalography \& Clinical Neurophysiology, 1965. $18,433-440$.

Fruhstorfer, H., \& Bergstrom, R. M. Human vigilance and auditory evoked responses. Electroencephalography \& Clinical Neurophysiology, 1969. 27. 346-355.

Garcia-Austt, E. Influence of states of awareness upon sensory evoked potentials. Electroencephalography \& Clinical Neurophysiology, 1963. 24, 76-89.

Rodin. E. A.. Grisell, J. I., Gudobba, R. D., \& Zachary. G. Relationship of EEG background rhythms to photic evoked responses. Electroencephalography \& Clinical Neurophysiology, 1965, 19, 201-204.

Salamy, A. The effects of alcohol upon sensory evoked and spontaneous cerebral potentials. Unpublished doctoral dissertation, Lniversity of Oklahoma, 1972.

Salamy. A. The effects of alcohol on the variability of the human evoked potential. Neuropharmacology, 1973, in press.

Shagass, C., Overton, D. A., Bartolucci. G., \& Straumanis, J. J. Effect of attention modification by television viewing on somatosensory evoked responses and recovery functions. Journal of Nervous \& Mental Disease, 1971, 152, 53-62.

Spilker. B., Kamiya, J., Callaway, E., \& Yeager, C. L. Visual evoked responses in subjects trained to control alpha rhythms. Psychophysiology, 1969. 5, 683-695.

Tanguay. P. E.. \& Ornitz. E. M. Two measures of auditory evoked response amplitude and their relationship to background EEG. Psychophy'siology, 1972, 9. 477-483.

Werre, P. F., \& Smith, C. J. Variability of responses evoked by flashes in man. Electroencephalography \& Clinical Neurophysiology. 1964, 17. 644-652.

(Received for publication A pril 25, 1973; revision received June 13, 1973; accepted August 3, 1973.) 